\title{
Applied Literature for Healing, Transformation and Empowerment
}

\author{
Susanna Marie Anderson \\ School of Graduate and Professional Studies, John F. Kennedy University \\ 100 Ellinwood Way, Pleasant Hill, CA 94523, United States \\ E-mail: ConsciousnessLit@gmail.com
}

Received: 26-05-2014

doi:10.7575/aiac.ijalel.v.3n.6p.89
Accepted: 04-07-2014

Published: 01-11-2014

\begin{abstract}
In this qualitative research study interviews conducted with elite participants serve to reveal the underlying elements that unite the richly diverse emerging field of Applied Literature. The basic interpretative qualitative method included a thematic analysis of data from the interviews yielding numerous common elements that were then distilled into key themes that elucidated the beneficial effects of engaging consciously with literature. These themes included developing a stronger sense of self in balance with an increasing connection with community; providing a safe container to engage challenging and potentially overwhelming issues from a stance of empowered action; and fostering a healing space for creativity. The findings provide grounds for uniting the work being done in a range of helping professions into a cohesive field of Applied Literature, which offers effective tools for healing, transformation and empowerment.
\end{abstract}

Keywords: Applied Literature, Bibliotherapy, Poetry Therapy, Arts in Corrections, Arts in Medicine

\section{Introduction}

\subsection{Applied Literature}

The field of Applied Literature (sometimes called Applied Language Arts), analogous to Applied Linguistics or Applied Physics, is an emerging branch of the field of Literature that intersects with the helping professions and is concerned with practical applications rather than abstract, theoretical discourses. The field is in its early stages of organization, and includes numerous approaches where professionals from various disciplines are consciously harnessing the transformative power of literature. Modalities explored within the scope of this research study include Bibliotherapy, Poetry Therapy, Personal Mythology work in Depth Psychology, and work being done in Education, Arts in Corrections and Arts in Medicine programs.

Engagement with literature has the potential to heal, transform, and empower individuals suffering from hardship and oppression to find meaning in all experience and take conscious control of their lives. This is a phenomenon that the researcher has personally experienced, and one that an increasing number of practitioners in various creative and helping professions feel driven to facilitate access to for a broader cross-section of the community.

This paper identifies commonalities across the diverse approaches in the field of Applied Literature in an effort to reveal the underlying processes at work. The transformative power of literature has broad implications for the realms of education, social services, mental health and medicine, criminal justice and public administration. Using literature in service of healing and psychological growth has a long history, but has yet to fully claim its place in the mainstream of the healing arts. Evidence is mounting, however, to support the claim that engaging with literature is a crucial part of evolving consciousness and empowering individuals and communities to more engaged and creative living. The parameters of this topic extend to include a broad range of approaches with the commonality that in all examples, engagement with literature serves as catalyst for healing, transformation and empowerment.

In completion of a Master's Degree in Consciousness and Transformative Studies at John F. Kennedy University, the researcher conducted a study of the impact and essence of Applied Literature approaches. Following a basic interpretative qualitative research method the researcher undertook a review of the literature informing this area of inquiry and conducted interviews with seven elite participants who spoke to their personal and professional experience of how engagement with literature can foster healing, transformation and empowerment. This paper addresses a gap in the literature by spanning the wide-ranging types of work being done in the realm of Applied Literature to illuminate the impact on the individuals and groups involved, to explore the core unity connecting the diverse methods and approaches, and to lay the groundwork for concerted efforts to facilitate the integration of Applied Literature practices across the helping professions.

\subsection{Review of the Literature}

The emerging field of Applied Literature encompasses numerous disciplines and varied approaches and the relevant literature represents that same diversity. Foundations are laid in the works of depth psychologists and literary theorists, 
applications are explored by librarians, social workers, and mental health practitioners, and research has been conducted and synthesized by psychologists and public policy experts.

\subsubsection{Foundations}

Swiss psychologist Carl Gustav Jung was one of the founders of depth psychology, and his final work: Man and his Symbols (1968), is an accessible introduction to the study of how the symbolic and archetypal realm plays an important part of humankind's evolution. In this work, Jung, along with his closest colleagues, elucidates the central ways that engaging with the symbolic or archetypal level of reality can be of great service both for the evolution of humanity as a collective, and in the personal individuation process. A central theme of this work is that engaging with the symbolic realm supports human development, as illustrated by the fact that such activities can be found across history, and across all human cultures to facilitate the creation of meaning and inspire individuals to live with purpose. The field of Applied Literature relates to this work, and Jungian psychology as a whole, as a solid theoretical grounding for the premise that engaging with literature is a valid, and indeed, vital activity for human development.

Northrop Frye was an influential Canadian literary theorist. In The Educated Imagination (1998), Frye poses and attempts to answer the question: "What good is the study of literature?" (p. 1). Frye (1998) offers the view that the archetypal story of the loss and regaining of identity is "the framework to all literature" (p. 21); reading therefore helps locate the individual within an ever-growing company of individuals on a similar journey of individuation. Engaging the imagination is of central necessity in cultivating the virtue of tolerance. The purpose of engaging with literature can therefore be distilled to an opening to the universal commonalities underlying the diversity of experience, fostering greater understanding of both self and other. Frye's work speaks to the central premise of this study of the transformative power of literature, and provides a theoretic grounding for the real world applications that follow.

American scholar Joseph Campbell (1991) brought mythology into the public consciousness in the popular six-part interview for PBS entitled "The Power of Myth". In the written account of this epic interview with journalist Bill Moyers, Campbell lays the foundation for his premise that myth is a natural and necessary component of human evolution. Campbell holds that our current western culture is starved for myth, and that connecting with the timeless archetypal stories of the human race can be therapeutic at both the individual and societal levels. In his conception, engaging with myth allows individuals to see themselves within the context of a universal struggle, empowering them to recognize their role in an ongoing human experience, and also contributes to inter-cultural understanding, as patterns are recognized and key themes resonate regardless of the specific details of cultural trappings. These two themes also emerged across the interviews with the elite participants as outcomes of their Applied Literature practices.

In Storied Lives: Discovering and Deepening Your Personal Myth, depth psychologist Craig Chalquist (2009) invokes the influences of C.G. Jung, Joseph Campbell and James Hillman, and outlines the approach of integrating mythology into a depth psychology perspective. In line with his predecessors, Chalquist (2009) declares: "The deep psyche speaks most naturally in symbols" (p.9), and explains that myth "bridges one's personal story to dimensions of experience that reach beyond the personal" (p. 4). His sentiment is in line with the assertion of Bibliotherapists that engagement with literature helps individuals come to new understanding of their own experience, including helping to locate it in the greater scheme of universal human experience. This stance unifies many of the works outlined in this brief review of the literature, and speaks to a central theme in this paper.

\subsubsection{Applications}

In Biblio/poetry Therapy, The Interactive Process: A Handbook, Bibliotherapy pioneers Arleen McCarty Hynes and Mary Hynes-Berry (1994) offer a clear and concise primer on Bibliotherapy as well as exercises and guidelines for training. The authors give this definition of the central term: "Bibliotherapy uses literature to bring about a therapeutic interaction between the participant and facilitator" (p. 17). McCarty Hynes and Hynes-Berry (1994) break down the heterogeneous field of Bibliotherapy into niche constituents with a primary focus on "Interactive Bibliotherapy" in which: "a trained facilitator uses guided discussions to help the clinical or developmental participant(s) integrate both feelings and cognitive responses to a selected work of literature" (p. 17). This interactive method is of primary interest to this paper, as compared to approaches that focus solely on prescribed reading or the role of didactic "self-help" books.

In Using Bibliotherapy: A Guide to Theory and Practice, Rhea Joyce Rubin (1978) — an experienced library consultant with a specialization in the field of Bibliotherapy - provides an extensively researched user's guide to the art and science of Bibliotherapy. Rubin chronicles Bibliotherapy's roots in psychology and library sciences, provides detailed accounts of how therapists, healthcare providers and librarians have successfully employed Bibliotherapy strategies over the years, and provides a thorough review of relevant literature and research. She also establishes guidelines for the selection of relevant and appropriate materials - in her estimation, the most crucial aspect of Bibliotherapy - and includes valuable appendices with source materials organized by theme.

In Bibliotherapy Sourcebook, Rubin (1978) complies a wealth of Bibliotherapy-related articles and materials and offers her own definition of this often contested term:

A program of activity based on the interactive processes of the use of print and non-print material whether imaginative or informational, facilitated by a librarian or other professional, to achieve insight into normal development or to effect changes in emotionally disturbed behavior. (p. Xi) 
This book offers the single best compilation of sources on this subject to date, including full-length articles discussing aspects of the work, an annotated bibliography, lists of theses and dissertations on Bibliotherapy, and suggestions for further reading.

John T. Pardeck (1998) is a professor of social work who, in Using Books in Clinical Social Work Practice: A Guide to Bibliotherapy, establishes Bibliotherapy as a valuable and widely used adjunct of therapy in social work. In his view, Bibliotherapy is not an independent therapy, but rather a valuable complement to a range of other treatment plans in clinical settings. Pardeck emphasizes the effectiveness of Bibliotherapy in service of self-development with relatively healthy and high-functioning individuals. Included in this work is a large index of "useful titles for clinical intervention" grouped by subject. While Pardeck's approach is grounded in social work rather than library sciences, and leans more toward non-fiction than fiction, this work stands as the closest thing to a sequel to the practical, unifying work that Rubin produced on the subject twenty years prior.

In his article entitled "The State of the Art of Poetry Therapy," Steve Rojcewicz (1999), psychiatrist and past president of the National Association for Poetry Therapy, chronicles the evolution of poetry therapy over history. He refers to the recognition of libraries as a places of healing by the ancient Greeks and Romans, cites poetry therapy's use in the first hospital in the United States, and chronicles current usage in a myriad of settings by practitioners certified by the National Association of Poetry Therapy. Rojcewicz (1999) outlines a range of therapeutic and developmental goals that can be met through "the intentional use of poetry and other forms of literature for healing and personal growth" including: "To promote change, increase coping skills, and improve adaptive functions to work through underlying conflicts...To enhance participants' self-understanding and accuracy in self-perception...To help participants integrate the different aspects of the self for psychological wholeness." (pp. 6-7) Through its historical re-cap of the field and its thorough examination of the different goals and approaches of Applied Literature, this article reveals the rich variations that have emerged in this work over time.

In his article "Souls in Jeopardy: Questions and Innovations for Bibliotherapy with Fiction," Psychologist Jonathan Detrixhe (2010) calls into question some of Bibliotherapy's standing assumptions and examines important considerations for undertaking this type of work. He notes that Bibliotherapy includes a range of practices, from cognitive behavioral approaches where prescribed self-help non-fiction books are seen as an alternative to one-on-one interaction with a therapist, to psychoanalytic approaches where the clinical relationship remains central to the process and where engagement with literature is cast as a tool with which to bring about interesting developments in the analysis of transference and alliance. Giving participants credit for the power of imagination and symbolic engagement, he argues for the benefits of drawing from a wide pool of literary experience, through which clients benefit from "having their imaginations kindled, their viewpoints challenged, and their life choices questioned but not resolved" (p. $65)$.

In Finding What you Didn't Lose: Expressing your Truth and Creativity Through Poem-Making, certified poetry therapist John Fox (1995) highlights the therapeutic elements of beauty and meaning-making found in engagement with poetry. Fox is one of the leading voices in the field of Poetry Therapy, and has further contributed to the field by founding a non-profit organization, the Institute of Poetic Medicine, in 2005.

In Fox's (1997) second book on the subject, Poetic Medicine: The Healing Art of Poem Making, he delves deeper into his study of applying literature in service of growth and transformation. In this work, Fox recounts evocative stories of transformation experienced by poetry circle participants. Here Fox moves into more specific applications including the relationship between creativity and healing, and how bringing the light of poetry to the darkness of illness, pain, and loss can be liberating for participants. This work also extends to include the intention of healing to the Earth as a whole, bringing an ecological aspect into the discussion, and engaging the grief and overwhelm that so many feel in the face of environmental crisis.

\subsubsection{Research}

James Pennebaker (1997), chair of the Department of Psychology at the University of Texas, summarizes several studies into the effects of writing as a means of therapy for individuals with trauma in his article entitled "Writing About Emotional Experiences as a Therapeutic Process." Pennebaker (1997) finds that "when individuals write or talk about personally upsetting experiences in the laboratory, consistent and significant health improvements are found...in both subjective and objective markers of health and well-being" (p. 164). Pennebaker is a prolific researcher and writer in the field of social sciences, and a forerunner in helping legitimize the claims of proponents of writing therapies through solid research.

Larry Brewster is a professional consultant and professor in the University of San Francisco's department of Public Administration who has spent years championing the positive impact of Arts In Corrections programs. In his 2010 paper, "A qualitative study of the California Arts In Corrections Program," he brings the stories of rehabilitation and transformation occasioned by this program to the public, in the form of a series of personal interviews. The basic premise of the work is that by affording inmates the opportunity to learn, grow and find means of creative expression, rather than simply wasting away or becoming embroiled in the detrimental elements of prison life, the positive outcomes are myriad. A landmark study conducted by Brewster in 1983 found the programs to be cost effective across a number of measures; his 1988 study found that there was a significantly lower recidivism rate for former participants of the program; and this latest qualitative study attests to the transformative power of engagement with the arts in helping inmates take agency and effect real change in their lives. 
In 2009, four leaders in the Poetry Therapy and Arts in Medicine fields: Ingrid Tegnér, John Fox, Robin Philipp and Pamela Thorne, conducted a pilot study entitled "Evaluating the use of poetry to improve well-being and emotional resilience in cancer patients." In this study, cancer patients participated in poetry therapy groups and completed selfassessments using four well-validated psychometric assessment tools both before and after the six week long intervention. The participants who received the poetry therapy intervention reported significantly lowered suppression of emotions and lowered anxiety in comparison to the control group. The authors suggest: "the use of poetry to heal offers people a sense of meaning and community that is rare within the highly clinical treatment environment" (Tegnér et al. 2009), and conclude that the results of this study were significant enough to offer initial support for the clinically measurable validity of using poetry therapy in service of emotional support and healing with cancer patients.

In an article entitled "Changing beliefs and behavior through experience-taking," Ohio State University and Dartmouth College researchers Lisa Libby and Geoff Kauffman (2012) investigated how readers' levels of identification and consequent "experience taking" with characters in a story affected their beliefs and even their actions going forward. It was found that participants who read a story in which the character was "different" from them (in race or sexual orientation) identified more with the character if the difference was revealed later on in the story. Furthermore, in postintervention testing those same participants demonstrated more positive views of the "other" group to which the character that they had initially identified with, belonged. This study has positive implications for Applied Literature approaches as valuable tools to constructively address issues of diversity, including prejudice, by cultivating empathy and broadening limited beliefs.

\subsubsection{Summary}

While the field of Applied Literature is still in its early stages of formalization, there exist rich sources informing this field of study. As seen in section 1.2.1, theoretical foundations for exploring the power of literature can be drawn from the fields of cultural anthropology and depth psychology. While not plentiful in comparison to other therapies, works addressing practical considerations for the implementation of Bibliotherapy in its various formats do exist, based on extensive in-depth efforts of a handful of impassioned individuals, as outlined in section 1.2.2. While momentum is beginning to build, the area of supporting research is the most under represented, and the studies that have been done are efforts to qualify and quantify the effects of specific Applied Literature therapies as summarized in section 1.2.3. This paper addresses a gap in the literature by offering a qualitative inquiry exploring the core commonalities across these varied approaches that unite them under the umbrella of Applied Literature.

\section{Method}

This study follows a basic interpretive qualitative approach to illuminate how people experience the power of literature, and how it can be consciously harnessed in support of healing, transformation and empowerment. The researcher interviewed elite participants from diverse fields with decades of personal and professional experience using Applied Literature practices.-A thematic analysis revealed common elements that arose in the interviews to highlight and further isolate the core processes involved across the rich and diverse array of relevant practices and interventions. These findings were then discussed and woven together to establish Applied Literature as a valid, valuable and unified field, and to lay the groundwork for further research and broader implementation at the community level.

\subsection{Participant Characteristics}

Elite participants were recruited from diverse fields where they have worked with a wide range of populations using Applied Literature interventions. The following list outlines the scope of the participant sample:

1. Rhea Joyce Rubin: A retired librarian, now library consultant, with years of experience in the field of Bibliotherapy, including multiple publications on the subject.

2. Curt Tofteland: An actor, director, and the founder of Shakespeare Behind Bars, a pioneering Arts in Corrections program that offers theatrical encounters with personal and social issues to incarcerated individuals, allowing them to develop life skills that will support their successful reintegration into society.

3. Rev. Jim Lawrence: A retired minister from a denomination with deep focus on canonical allegoresis, now Dean of the Swedenborgian House of Study at the Pacific School of Religion, a progressive, pandenominational ecumenical seminary.

4. Natalia Tukhareli: A librarian who implemented a successful Bibliotherapy program at Nkosi's Haven, a shelter for women and children with HIV/AIDS in South Africa, and who founded a Toronto based non-profit, Read To Connect, which offers Bibliotherapy to empower individuals to take effective actions on their health and well-being to improve the dignity and quality of their lives.

5. John Fox: A certified poetry therapist, author of multiple publications on the subject, and the founder of the Institute for Poetic Medicine, a non-profit dedicated to healing body, mind and spirit through the creative and therapeutic process of hearing and writing poetry.

6. Emilie Coulson: Former Director of Education at 826 Valencia, a non-profit dedicated to supplementing the education of students ages $6-18$ by facilitating their access to the literary arts, and by helping teachers get their students excited about writing. 
7. Craig Chalquist: A depth psychologist and graduate professor with expertise in the area of archetypal mythology, founder of the field of Terrapsychology, with multiple publications exploring how story and myth relate to personal and collective consciousness.

\subsection{Research Steps}

The researcher conducted interviews asking all elite participants the same basic questions about their experience with Applied Literature. Each participant had their unique perspective, however, in many areas common through lines and essential values emerged. Embracing the qualitative method's willingness to accept the involvement of the researcher's consciousness, the researcher asked clarifying questions to further hone in on emerging common themes, and to engage in a creative interactive process of research cycling within the course of the interviews.

\subsection{Data Collection and Analysis}

The researcher recorded and transcribed all seven interviews, and subsequently coded and analyzed the transcripts in order to distill the universal elements of the Applied Literature approaches across various fields. A thematic analysis that included the process that Phenomenologist Moustakas (1994) calls horizontalization was followed, wherein data gleaned from participants is analyzed and distilled into a collection of significant statements, which are then organized into "clusters of meaning"- further streamlining and distilling those significant statements into their essential core meanings (Creswell, 2007, p. 61). The interpretations presented in this paper are based on patterns that emerged in the data analysis stage, which revealed an initial 27 common themes that arose in multiple interviews. The sheer wealth of common ground was fascinating and validated the premise that the commonalities uniting these various approaches into a larger field of Applied Literature were an area deserving attention. The significant statements were woven into larger thematic clusters of meaning that spoke to a few central processes at work that arose across the interviews.

\section{Findings}

The data revealed that interaction with literature served healing, transformation and empowerment in multiple complex and interrelated ways. These findings were distilled to the overarching themes discussed here, and are presented drawing on excerpts from the interviews.

The development facilitated by engagement with literature was revealed as a reflexive process whereby the participants' sense of self deepened through an increased sense of autonomy and unique identity, while also expanding horizontally by virtue of a growing conception of embeddedness in a larger community. The interviews showed that creating a safe container is of central importance in this process, and that Applied Literature approaches facilitated this safe container through the use of story, metaphor and symbolic language, as well as by virtue of the group dynamics that were seen to arise within the approaches discussed. The importance of the creative act catalyzed by engagement with literature and how it supports health and empowerment was also widely stressed, and finally, the high emphasis placed by participants on facilitating broader access to Applied Literature practices, normalizing the process and cultivating these approaches as lifelong resources is also explored.

\subsection{Reflexive Development of Individual and Communal Self-Awareness}

One key aspect of how literature can heal, transform, and empower that emerged over the course of the interviews related to an evolving sense of one's uniqueness; its counterpart showed how important it was that this was situated in, and enhanced by, an evolving sense of embeddedness in the community of universal human experience. These two complementary and reflexive themes arose on numerous occasions throughout the interviews.

Craig Chalquist explained why literature is so well suited for catalyzing transformation: "There's so much psychological wisdom in literature. As James Hillman said: 'You don't find much psychology in psychology books, but you find it a lot in humanities'...I've always used literature as a primary source for wisdom about human nature." With a similar sentiment Curt Tofteland explained why he goes beyond the act of reading in his Shakespeare Behind Bars groups, as he feels that the act of performance best capitalizes on the "in-depth exploration of the human condition" that is offered by engaging with literature. The examples that follow illustrate that the wisdom born out of engagement with literature can be applied equally well both intra- and inter-personally.

\subsubsection{Individual growth, healing, self-knowledge}

One of the ways in which literature was seen to facilitate greater self-understanding is in how it allows one to access another mind, another experience, which then informs the understanding of one's own. In describing the outcomes of his work with personal mythology both in private clinical practice and in groups and classroom settings, Chalquist said: "I see people all the time who suddenly get why they are the way they are."

A common concern that came up in this area of discussion was supporting participants to claim space for their unique voice as a major source of empowerment. Emilie Coulson spoke of how their work at 826 Valencia seeks to show youth that "their stories have a space too, their stories have an audience," and later described how the youth come to embrace the experience, as it "offers them a platform that they may not have had before."

Tofteland said that he seeks to address "the big questions" with his participants, one of which is: "Who am I?" That part of the work, he said, often culminates with engaging scenes from Hamlet, where he felt Shakespeare "explored the deepest inner world". He uses this process to help the incarcerated men in his groups shift the locus of responsibility for defining their identity inwards: "Because 'Who am I?' can't be defined by external means...the only one who can dictate who you are is you...And Hamlet holds the mirror up and we use that metaphor of who lives inside? Bring it 
forth!" This speaks to learning from positive examples and authentic inquiry modeled in great literature, and also how the process of engagement with literature opens up new opportunities for self-exploration and self-expression. Just as the youth in the writing and publishing workshops may not have had that forum for expression before, these prisoners, many of whom come from pasts fraught with complex trauma and socio-economic challenges, may not have previously had the psychological forum that allows this type of active introspection.

One of the central ideas in Bibliotherapy is the power of "identification" (Rubin, 1978; Hynes-Berry \& McCarthyHynes, 1994); the reader's ability to identify with the character and the impact that can be felt when there is a strong sense of identification. A powerful illustration of this process came from Natalia Tukhareli's description of how the residents at Nkosi's Haven, the Johannesburg shelter for women and children with HIV and AIDS, responded to a book about a young woman who was born HIV positive. Tukhareli said it was striking how enrapt the women became upon finding someone with whom they could identify in a book that portrayed a rich and love-filled life, held in balance with a poignantly realistic portrait of the impact of HIV and AIDS in the lives of the characters. Tukhareli recalls how when she arrived at the shelter, the director warned her to set realistic expectations as the women were "not interested in anything." When she presented them with this book, however, Tukhareli recalls:

It turned out that it all changed... I remember their eyes; they just opened wide...it was amazing...for them it was a breakthrough. And then [one woman] borrowed this book, and one by one they all borrowed this book. And [one] said "you know, this book gave me hope".

In this instance, by offering clearly accessible connections to the reader's life, Bibliotherapy occasioned a meaningful shift for these women; it gave them hope and empowered them to think of their lives and their futures in a new light. One young, homeless, HIV positive single mother said: "During our workshops, I felt like you were watering something inside me and I was changing, like blossoming." Tukhareli recalls with pride and admiration how this woman gained a more empowered sense of identity through the course of their Bibliotherapy workshops. In the aftermath of the Bibliotherapy sessions the woman quoted here and several of her peers were able to move forward in concrete proactive ways, gaining employment and successfully transitioning out of the shelter.

\subsubsection{Finding self in relation to others}

John Fox, certified poetry therapist and non-profit founder, noted "when people in a group read their work over a period of time they begin to realize that nobody's voice is like anybody else's voice." This theme of finding one's unique voice was recurrent through several interviews, especially in the applications that involved writing or performance. When Fox was asked how the deepening sense of community related to this unfolding sense of individuality he took this idea one step further:

If it was only that everyone's voice is unique we might end up feeling alienated... my sense is that even though everyone has a unique way of viewing things, people find common ground...There's a sense of learning from each other, and common experience.

This speaks to the dialectic process by which Applied Literature approaches make their impact. There is simultaneously an increase in the individual's sense of self as a unique and valuable individual, and also a growing bond with others that comes out of the recognition of common ground, and the empathy that arises in light of this sense of community. Tukhareli identified the latter phenomenon as "universalization", a term that describes the ability to connect through finding common ground, often cultivating empathy, hope, and empowerment.

Many participants pointed out that part of what facilitates transformation in the lives of individuals engaging these approaches is the ability to connect with others. This connection can happen indirectly, across time and space between an author who once upon a time put words on a page and a reader who one day finds solace, community, or inspiration in those words. It can happen in person, when participants of a Bibliotherapy group share reactions aloud, and learn how a piece of literature impacts others in ways that are startlingly similar, or thought provokingly different, and that prompt them to engage in dialogue. It can happen when an actor or reader begins to inhabit a character, and takes on that new identity and way of being in the world, taking advantage of opportunities to experience lives, actions, and consequences quite apart from his or her everyday narrowly circumscribed existence. And it can happen when giving expression to one's voice through the expressive arts like poetry therapy, where giving shape and voice to one's creation is often described as an intensely transformative and empowering experience.

Fox quoted the moving response of a poetry therapy participant who, upon reading a poem aloud and seeing the response it elicited in others, said: "I felt that I was returning to a world where I felt seen, heard, understood, and cared for." The ability to foster understanding, to cultivate empathy and support, and to empower through strength in connection was present in some way in all of the interviews. Some participants stressed the importance of the bond that arises between facilitator or therapist and the participant. Some stressed the importance of connection that grows between group members when sharing occurs and empathy is cultivated, and some stressed the broader sense of connection that arises from the simple realization that "there are others like me, dealing with what I have dealt with." The rich descriptions shared by the participants are compelling evidence of this essential common element across Applied Literature approaches.

\subsection{Providing A Safe Container}

The participants' statements revealed a particular way in which engagement with literature assisted in individual healing and empowerment by providing a "safe container" for a therapeutic experience. Tukhareli shared: 
My belief is that literature can provide individuals with a safe environment, a safe channel for addressing their issues and problems. While discussing a fictional character that dealt with the same problem, people have a chance to freely talk about their own issues and gain a fresh perspective on their own situations or even find alternative solutions to their problems.

Many examples came up that supported the idea that employing the media of literature can facilitate engaging with difficult subject matter. In Applied Literature approaches focus is shifted away from the individual who is embroiled in the challenging situation, to a more neutral character in a story or play in whom the individual can in some way experience a reflection. This shift allows the critical distance necessary from which to gain an outside perspective on one's own problems, which can often free up new ways of seeing things and new insights for action that would otherwise be inaccessible.

Coulson said: "Fiction allows us to tell our own stories through a safer means...Stories have so much power to get us talking, get us to communicating things that we don't have anywhere else to put, we see it here all the time." She, like several participants, spoke to the benefits of both autobiographical storytelling and fiction, and how these frameworks allow the individual to entertain new ways of engaging and working through difficult issues.

Fox recalled working with a man struggling to deal with the fact that his wife had cancer. The man wrote a poem about it and shared it with his wife, which opened the space for a deep and honest conversation about this difficult issue. Fox recalls: "he learned a tremendous amount from her about what it means for her, and also that there were layers of it for himself." Sometimes, it seemed from the participants' descriptions, simply having another forum that allows for the exploration of difficult subject matter in a manner outside the everyday rational, left brain modality can be very effective at unlocking insight and tilling the soil for new action. Fox remarked that, "the elements of poetic language help people to feel into difficult and complex situations" and he spoke of witnessing his poetry group participants come to "the understanding that even something difficult can bring meaning."

Rhea Joyce Rubin, recounting her experiences conducting Bibliotherapy groups with men and women in prison, spoke to the fact that the dynamic of trust and inquiry established in their groups "got the participants talking about very important stuff that is taboo to talk about in prison." Similarly Tofteland described the milieu he creates in his groups as "a circle of safety" and described how the men he works with share things, both in their private journal exchanges with him, and in the group discussion settings, that they do not have the opportunities to share elsewhere. He said: "they feel safe, and they get it out, and they're able to examine it."

Chalquist described how a science fiction novel brought about "a great discussion about peoples' views about technology and how they feel about what its shadows are" in one of his graduate classes, and spoke to how literature can provide the type of safe container necessary to engage overwhelmingly large-scale complex realities like the current ecological crisis: "I've been telling environmentalists that trying to wake people up to the crises we're facing can actually be counterproductive, unless you give them a container to hold it with." In these examples, engaging with literature or storytelling can help individuals and communities confront the serious and urgent issues facing our world today in a way that empowers them to engage with these issues with heightened consciousness and empowered creativity.

\subsection{The Role of Creativity}

Many participants described how the creative aspect of engaging with literature, be it through writing, reading, discussing, or performing, offers a unique healing opportunity. Fox, who has worked extensively with hospitals and hospices that integrate holistic Arts in Medicine approaches, said: "in particular, dealing with things...that are particularly difficult, creativity gives a way to hold it that [is] not overwhelming." Tukhareli echoed this sentiment:

The author who creates his world in a novel, a story or a poem engages a reader in a complex process of recreating this world during the reading process. While recreating this world, however, the reader has always a chance to project the fictional world into his own life and "live" his own situation through the narrative of the book. And this is a moment when a "healing," "consoling" or "transforming" power of a book occurs.

The idea that invoking imagination through the stimulation to situate oneself in relation to the characters is a healthy and creative act helps explain the healing power of this work.

Rubin honed in on the transformative aspect of engaging with literature: "The closest I get [to explaining it] is...identifying with a book, and then realizing the book ends differently, which makes you think 'why couldn't my life go that way if I want?'... The core thing is experiencing another life." Several participants spoke to how engaging with literature helps one get beyond limited self-identification and allows space to open up for a creative, newly broadened perspective on one's life situation.

Fox had an interesting take on the important role of creativity in the human experience. He described seeing "a real increase in self-awareness and empowerment through the creative process," and said: "I'm interested in the possibilities of creativity in human beings, maybe in particular in the form of language... it has a real immune function to it." This casts Applied Literature approaches as satisfying a core evolutionary need for balancing and embracing the dynamic inter-relatedness of the many systems of which we are comprised and in which we exist. Along these lines Tofteland said outright: "we're narrative creatures...I just think fundamentally we are all creatures of metaphor." This comment likewise underscores that human consciousness thrives in the complexity of symbol and metaphor, well beyond the scope of a literal, atomistic, materialist worldview. 


\subsection{Facilitating Shifts in Perspective}

One of the greatest overarching themes that can be seen at a meta-level to encapsulate the themes discussed in sections 3.1-3.3 relates to how engagement with literature facilitated a positive shift in perspective. The action of shifting perspective is what creates the moments of insight that offer new space for ideas and inspiration for change. Rubin said: "the trick in Bibliotherapy is to pick the books you think will be really relevant or touch some cord to really open people up to talk and get a new perspective." Throughout the seven interviews, facilitating a meaningful shift in perspective was cast as a central goal of Applied Literature approaches.

Using literature to support the shift from limited identification or valuation of objective or "absolute" truth, to move toward incorporating space and value for the subjective and relative realities was a specific aspect of this overarching theme that came up in several interviews. Rev. Jim Lawrence, minister and religious studies professor, qualified his enthusiasm for the power of insight gleaned through engagement with literature by saying: "That doesn't mean it's true on an objective level, but...that it's really effective for me to put together interpretations of the world I live in, and of human interactions, and in life that feels really important." This expansion on the theme of shifting perspective from a strictly existential to a more abstract philosophical level speaks to how we can use these practices to consciously support an evolving multi-perspectival vision.

For Tofteland, this theme came up as he heralded the eminent value of Shakespeare's "ambiguity" as it plays out in his work in the correctional system:

I have guys who are very literal, and then start to open up the symbolism of what happens underneath... if they all do the "to be or not to be" monologue, for 23 different guys we'd have 23 differently nuanced interpretations. I like to live in the nuance and differences. But I have literalists who say, "No it can't mean that, it means this". I say fine if that's what it means to you-just don't force that on someone else. Its amazing the discussion we have! You'd walk in (and I've had academics do this) and swear everyone in there was working on a PhD, that's the level of passion they have for the subject, and depth of knowledge they have, and the civil discourse.

Nuanced interpretations, depth of knowledge, civil discourse; these are not words most would expect to hear used to describe prison inmates, but the Applied Literature work that Tofteland is doing with these men clearly elicits real and marked transformation which begins with opening up to other perspectives.

Lawrence explained: "the way our minds are structured is such that symbols are a hinge for our consciousness." A large part of how this function of Applied Literature works is by helping participants open up to this abstract, symbolic realm that brings about an invigorating and empowering new perspective; a new perspective that can help individuals and communities make meaning in healing ways, even in the face of great hardship or crisis.

\subsection{Broader Access, Normalizing and Sustaining Long Term Engagement}

The issue of access concerned the majority of participants, and many offered compelling arguments for the value of promoting literature, and more broadly, a renewed emphasis on arts and humanities as a whole, for the transformative role they can play both in the individual and collective spheres. Several of the participants spoke with concern about the state of the current mainstream education system and how its values generally run counter to this perspective. The participants all also spoke to the value of engaging literature to create a life of sustainable wellness and growth, and many participants stated their desire to render these transformative practices more accessible to the community at large. Fox explained: "What I feel is the most challenging aspect is people feel you have to be something 'special' or this is not going to work...for me that is half the battle, that people can have access to this work." Normalizing Applied Literature approaches was a goal voiced by all the participants; integrating these tools, modalities and practices into regular everyday life, and imparting the idea that engagement with the arts is not for "artists" alone. Fox described cultivating unconditional acceptance of the creative process, both for the individual to hold a less critical attitude toward their own process, and also to bring to group settings where members are sharing their experience or work. Fox uses a poem by Charles Olson that has the phrase "keep the roots on" which he uses to underscore his heartfelt injunction that "you don't have to make it nice!" Tofteland similarly voiced this sentiment at a philosophical level, declaring the true orientation of the artist as: "seeking not for perfection, but for wisdom". Facilitating access by distinguishing Applied Literature, like any expressive arts therapy, from art that is created in pursuit of aesthetic beauty was of central importance to several participants.

On the subject of long term outcomes Tofteland described how he has witnessed the impact that his program has on its inmate participants, and how, over time, they become changed and empowered by the fact that "they realize they have an intellect, they're not stupid, not the failure always told they were, and self esteem comes up, and hunger, the passion." It appears that the benefits from the work operate on many levels; in addition to the psychological growth that can be catalyzed by engagement with the symbolic, there is also the empowering aspect of opening a new world of literature to participants, a world which perhaps they had thought was not for "people like them." This comes back to the issue of access, and speaks to how empowering it can be to open up new worlds of stimulation, expression and meaning through engagement with literature.

When asked how he has witnessed the impact of this work, Lawrence discussed how in his eyes, there is an important second part of the work that comes after the insight, which requires "discipline, and courage to change." He identifies both components of the process as having distinct yet complementary integrity, explaining: "I do trust the insight piece as having something ontologically real to it... [but] there's something to discipline and practice that is post- 
transcendence, post-breakthrough that is really crucial, or you'll just keep doing the same thing over and over again.” This is a valuable distinction to keep in mind-insight is not everything - that is crucial to a pragmatic Applied Literature approach that seeks to cultivate real and lasting personal or collective evolution. Lawrence spoke about the importance of being in community with others in this process, a theme that also came up throughout the interviews as one of the best ways to ensure the accountability and support needed so that the transformations in consciousness that occur as a result of engagement with literature are brought to fullest fruition.

\section{Conclusion}

In this qualitative research paper a review of the literature and the findings from interviews with seven elite participants serve to illustrate the underlying elements that unite the richly diverse field of Applied Literature. A thematic analysis of the data from the interviews revealed common themes that elucidate the beneficial effects of engaging consciously with literature, including a reflexive development of a stronger individual sense of self in balance with an increasing connection with community; the importance of the safe container this work provides which enables participants to engage challenging and potentially overwhelming issues from a stance of empowered action; and its value in fostering a healing space for creativity.

The field of Applied Literature offers a range of approaches that serve to facilitate healing, transformation, and empowerment. These practices are especially powerful in offering ways of holding and consciously engaging challenges or adversities, and paving the way to move forward in empowered action. In the face of far-fromequilibrium ecological, political, sociological and economic systems, the inexpensive and easily accessible transformative power of literature is a resource that we would do well to harness through concerted inter-disciplinary efforts. Efforts to render these practices more broadly accessible to the community at large will allow us to individually and collectively face the great challenges of our time with insight, empathy, and conscious agency.

\section{References}

Brewster, L. (2010). “A qualitative study of the California Arts-In-Corrections Program” San Francisco, CA: University of San Francisco.

Campbell, J. (1991). The power of myth: With Bill Moyers. New York, NY: Anchor Books.

Chalquist, C. (2009). Storied lives: Discovering and deepening your personal myth. Walnut Creek, CA: World Soul Books.

Creswell, J. (2007). Qualitative inquiry and research design: Choosing among five approaches. Thousand

Oaks, CA: Sage Publications, Inc.

Detrixhe, J. (2010). "Souls in jeopardy: Questions and innovations for Bibliotherapy with fiction" Journal of Humanistic Counseling, Education and Development. 49, 58-72.

Fox, J. (1995). Finding what you didn't lose: Expressing your truth and creativity through poem-making. New York, NY: G.P. Putnam's Sons.

Fox, J. (1997). Poetic medicine: The healing art of poem-making. New York, NY: G.P. Putnam's Sons.

Frye, N. (1998). The educated imagination. Toronto, Canada: House of Anasip Press Ltd.

Hynes-Berry, M. \& McCarthy-Hynes, A. (1994). Biblio/poetry therapy-the interactive process: A handbook. St. Cloud: North Star Press.

Jung, C.J. (1968). Man and his Symbols. New York: Dell Publishing.

Kaufman, G. \& Libby, L. (2012) "Changing beliefs and behavior through experience-taking." The Journalof Personality and Social Psychology 103.1 (Jul): 1-19

Moustakas, C. (1994). Phenomenological research methods. Thousand Oaks, CA: Sage Publications, Inc.

Pardeck, J. (1998). Using books in clinical social work practice: A guide to Bibliotherapy. Binghamton, NY: The Haworth Press, Inc.

Pennebaker, J. (1997). "Writing about emotional experiences as a therapeutic process". Psychological Science. 8, 162166.

Rojcewicz, S. (1999). "Medicine and poetry: The state of the art of poetry therapy". International Journal of Arts Medicine, 6(2), 4-9.

Rubin, R.J. (1978). Bibliotherapy sourcebook. Phoenix, AZ: Oryx Press.

Rubin, R.J. (1978) Using bibliotherapy: A guide to theory and practice. Phoenix, AZ: Oryx Press.

Tegnér. I., Fox, J., Philipp, R. \& Thorne, P. (2009). "Evaluating the use of poetry to improve resilience in cancer patients". Journal of Poetry Therapy. 22(3), 121-131. 